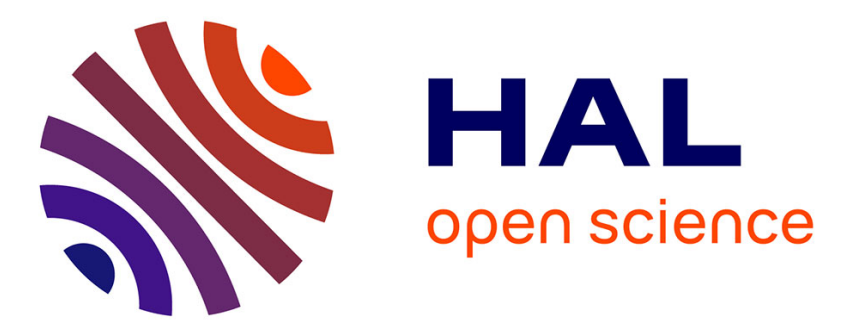

\title{
Pollution-induced community tolerance for in situ assessment of recovery in river microbial communities following the ban of the herbicide diuron
}

S. Pesce, C. Margoum, A. Foulquier

\section{- To cite this version:}

S. Pesce, C. Margoum, A. Foulquier. Pollution-induced community tolerance for in situ assessment of recovery in river microbial communities following the ban of the herbicide diuron. Agriculture, Ecosystems and Environment, 2016, 173, pp.120-131. 10.1016/j.agee.2016.01.009 . hal-01804840

\author{
HAL Id: hal-01804840 \\ https://hal.science/hal-01804840
}

Submitted on 1 Jun 2018

HAL is a multi-disciplinary open access archive for the deposit and dissemination of scientific research documents, whether they are published or not. The documents may come from teaching and research institutions in France or abroad, or from public or private research centers.
L'archive ouverte pluridisciplinaire HAL, est destinée au dépôt et à la diffusion de documents scientifiques de niveau recherche, publiés ou non, émanant des établissements d'enseignement et de recherche français ou étrangers, des laboratoires publics ou privés. 


\title{
Pollution-induced community tolerance for in situ assessment of recovery in river microbial communities following the ban of the herbicide diuron
}

\author{
Stéphane Pesce ${ }^{1}$, Christelle Margoum ${ }^{1}$, Arnaud Foulquier ${ }^{1,2}$
}

1. Irstea, UR MALY, Centre de Lyon-Villeurbanne, 5 rue de la Doua, CS70077, 69626 Villeurbanne Cedex, France

2. Laboratoire d'Écologie Alpine, UMR 5553 CNRS, Université Grenoble Alpes, BP 53, 38041 Grenoble Cedex 9, France

Corresponding author : Stéphane Pesce - stephane.pesce@irstea.fr

\section{Highlights}

- We performed a 3-year survey in a vineyard river long exposed to diuron.

- The ban on diuron resulted in a gradual fall in its concentrations in the river.

- A PICT approach was used to assess tolerance of phototrophic biofilms to diuron.

- A progressive decrease in tolerance was detected.

- PICT has great potential to assess microbial recovery following chemical restoration.

\begin{abstract}
Changes in agricultural practices related to environmental policies such as the European Water Framework Directive should lead to a decrease in pesticide contamination levels in rivers draining agricultural areas. However, there is still a need for biological tools to evaluate resulting ecological changes, namely to evaluate ecological recovery following the improvement of surface water chemical quality. Accordingly, the main purpose of this study was to assess the relevance of a pollution-induced community tolerance (PICT) approach in natural phototrophic biofilms to estimate microbial community recovery following a decrease in diuron contamination due to the ban of the use of this herbicide on vineyards. To this end, we performed a 3-year field study (2009-2011) in the Morcille River (France), located in the French Beaujolais wine region. This river was frequently contaminated by diuron (among other organic and inorganic pesticides), with increasing concentrations downstream. Following the ban on diuron, imposed in December 2008, a progressive decrease in diuron concentrations was observed in the Morcille River. While the mean annual tolerance levels measured at the low contaminated station remained relatively constant over years, a clear and significant decreasing trend was observed at the medium and high contaminated stations during the survey. This temporal evolution revealed a direct link between a change in agricultural practice due to the ban of diuron and an increase in the sensitivity of phototrophic biofilms to this herbicide. This finding brings further new evidence that PICT has great potential to detect microbial community recovery following chemical restoration due to changes in the agricultural use of pesticides.
\end{abstract}




\section{Keywords}

Agricultural pesticide use; Biofilms; Ecological recovery; Microbial ecotoxicology; Periphyton; PICT

\section{Introduction}

In a context of increasing pressure on global water resources, the restoration of impacted aquatic ecosystems has become a major concern, prompting the $E U$ to propose the European Water Framework Directive (WFD, 2000) that initially aimed to achieve good chemical and ecological status of water bodies by 2015. A key aspect of the WFD is to go beyond the estimation of pollutant concentration to take into account the ecological effects of pollution on ecosystem structure and functions. Even though WFD monitoring for the first river basin management plan was focussed on characterizing the present status of a water body, the ultimate aim is to assess the improvement of ecological status following restoration measures (Hering et al., 2010), which poses the scientific challenge of translating data on biotic communities into information for assessing ecological recovery.

Among other measures, specific measures were adopted to regulate chemical pollutants. A first list of 33 priority substances was thus established and many of them have since been banned in several EU states. This is the case of the photosystem II (PSII) herbicide diuron (3-(3,4-dichlorophenyl)-1,1-dimethylurea), which was banned in France in December 2008 (Official Journal of the French Republic, \#204; 04.09.2007) in application of EC directive $2007 / 417 /$ EC. Before its ban, this herbicide was frequently used in agricultural and urban environments leading to severe contamination of surface waters. This was notably the case in small streams draining wine-growing areas (e.g. Louchart et al., 2001 and Rabiet et al., 2010). A recent study, performed in the French Beaujolais wine region demonstrated that banning diuron, which was frequently applied to vineyard soils, resulted in a progressive decrease in diuron concentrations in a small adjacent stream (Morcille River) over a fouryear survey period (Pesce et al., 2013). The authors showed that chemical restoration following chronic diuron exposure ran paralleled with a progressive fall in sediment diuronmineralizing capacities, revealing a corresponding biological recovery of microbial communities. This finding points to benthic microbial assemblages as useful potential indicators of ecological status as previously stated (Burns and Ryder, 2001 and Sabater et al., 2007).

Several field studies have shown that in situ diuron exposure can enhance the tolerance of phototrophic biofilms towards diuron ( Dorigo et al., 2007 and Pesce et al., 2010b). This is in line with the concept of pollution-induced community tolerance (PICT), first introduced by Blanck et al. (1988), which postulates that chronic exposure to pollutants would exert a selection pressure on natural communities, thus eliminating sensitive species and thereby increasing tolerance at the community level. When studying the effects of phenylureas or other PSII-inhibitor herbicides, the PICT method is generally applied using photosynthetic activity as endpoint (Pesce et al., 2011) and, increasingly, using multiwavelength-excitation PAM fluorometry for the toxicity assessment (Schmitt-Jansen and Altenburger, 2008). PICT approaches based on short-term photosynthetic bioassays were successfully applied to assess the potential of natural phototrophic biofilms to recover after a decrease in herbicide exposure, using in situ translocation from polluted sites to reference sites ( Dorigo et al., 2010a, Dorigo et al., 2010b and Rotter et al., 2011). These studies showed a decrease in tolerance capacities towards the most predominant herbicide in the rivers studied (diuron and 
prometryn, respectively) after just a few weeks at the reference sites. Accordingly, it was concluded that biofilm recovery capacity could offer a suitable management tool for evaluating recovery processes in freshwater ecosystems, especially in PICT-based approaches ( Dorigo et al., 2010a, Dorigo et al., 2010b and Rotter et al., 2011). This is in line with the conclusion from a group of European researchers dealing with aquatic microbial ecotoxicology, who recently underlined the relevance of PICT for ecological risk assessment of chemicals in aquatic systems (Tlili et al., 2016).

However, biofilm recovery is an ecological process that is at least partially driven by immigration of non-exposed organisms (Morin et al., 2012). One limit of translocation procedures for microbial community recovery studies consists in the fact that immigration processes, and consequently recovery trajectories, are probably facilitated since the exposed biofilms are transplanted into river sections colonized by indigenous communities. This enhanced recovery in presence of non-previously-exposed (i.e. "pristine") communities was also clearly revealed in a microcosm study showing with a PICT approach that recovery processes (i.e. a decrease in level of tolerance to copper) were only observed in phototrophic biofilms in contact with pristine biofilms ( Lambert et al., 2012). Moreover, recovery studies based on translocation manipulations are generally relatively short (i.e. several weeks) and performed in sites exhibiting marked pollution gradients. Consequently, the use of the PICT approach needs to be validated in a context of long-term and progressive change in chemical river quality, as previously shown in a marine environment (Blanck and Dahl, 1998).

Considering this background, the present study aimed to assess the relevance of PICT approaches in natural phototrophic biofilms to estimate microbial community recovery following a decrease in herbicide exposure. Accordingly, we performed a 3-year field study (2009-2011) in the Morcille River (France), which was frequently contaminated by diuron (among other organic and inorganic pesticides), with increasing concentrations along an upstream to downstream gradient (e.g. Montuelle et al., 2010 and Rabiet et al., 2010). During the 3-year survey period, biofilm samples were collected monthly at three sampling stations distributed along the Morcille River and which are respectively located in the upstream (i.e. "low contaminated"), intermediate (i.e. "medium contaminated") and downstream (i.e. "high contaminated") sections. Temporal and spatial analysis of the capacity of phototrophic communities to tolerate diuron was performed using short-term photosynthetic bioassays. An extensive chemical survey was performed concomitantly to determine whether the evolution in tolerance levels reflected the post-ban decrease in diuron exposure levels in this stream.

Firstly, and according to the steady low level of diuron exposure recorded in the upstream river section, it was expected that the tolerance levels measured at this station would have been low and relatively stable over the survey period. Confirmation of this hypothesis would support the choice of considering biofilms from the upstream low contaminated station as reference communities. Secondly, we hypothesized that the tolerance of phototrophic biofilms towards diuron, which was previously shown as significantly higher in the high contaminated station when diuron was still used (Pesce et al., 2010b), would have progressively decreased in the medium and high contaminated sections in response to the decrease in diuron exposure level following the ban of its use in vineyard treatments. Confirmation of this hypothesis would support the relevance of the PICT approach in our study case. Finally, we discussed possible improvements and perspectives for the development of such approaches in water ecological quality assessment. 


\section{Materials and methods}

\subsection{Study site}

The Morcille River (southeastern France, longitude $4^{\circ} 60^{\prime} \mathrm{E}$, latitude $46^{\circ} 15^{\prime} \mathrm{N}$ ) is located within the Beaujolais area, which is a large wine-producing region in France. It is a small first-order stream (7 km long), and the surface of its watershed is about $8.8 \mathrm{~km} 2$. The head of the watershed basin is essentially covered by forest, whereas vineyard is predominant in the downstream section of the watershed, covering about $85 \%$ of the catchment's total area (Rabiet et al., 2015). The Morcille banks are well-vegetated with trees from upstream to downstream and no industrial activities are present on the site. The Morcille River flows continuously and varies widely over the year, with instantaneous water flow ranging from $0.005 \mathrm{~m} 3 / \mathrm{s}$ (low-water period) to more than $0.5 \mathrm{m3} / \mathrm{s}$ (during storms) (Rabiet et al., 2015).

The Morcille watershed, which is part of the Long-Term Ecological Research Rhône Basin (LTER ZABR), is dedicated to the long-term study of the environmental impact of diffuse pollution by metals and pesticides (e.g. Dorigo et al., 2007, Montuelle et al., 2010 and Rabiet et al., 2015). Even if most of chemicals enter the Morcille River via diffuse pollution from adjacent fields (which are separated from the river by grass buffer strips), several point sources exist, such as small agricultural ditches collecting concentrated subsurface lateral flow and drain discharges.

Heavy metal contamination in the Morcille is mainly due to copper and arsenic (Montuelle et al., 2010 and Rabiet et al., 2015) with recorded concentrations remaining relatively constant over the last 10 years. Before its ban, the herbicide diuron was the most commonly used herbicide on the Beaujolais vineyards, the main application period being April-September, according to climatic conditions. Accordingly, diuron was the most predominant pesticide in the Morcille River (Rabiet et al., 2010) with dissolved concentrations being sometimes higher than $10 \mu \mathrm{g} / \mathrm{L}$ (Pesce et al., 2009). The Morcille River has been subjected for many years to a chronic contamination by the herbicide norflurazon, a carotenoid-biosynthesis inhibitor banned in France since 2003, and its desmethyl metabolite, revealing its persistence in the environment. In the most contaminated section of the Morcille River (i.e. downstream section), mean annual concentrations of norflurazon and desmethyl norflurazon are generally between 0.15 and $0.25 \mu \mathrm{g} / \mathrm{L}$ and 0.90 and $1.40 \mu \mathrm{g} / \mathrm{L}$, respectively, with seasonal variations reflecting climatic and hydrological conditions (unpublished). Other photosystem inhibiting herbicides (e.g. atrazine and its main metabolites, simazine, terbuthylazine, isoproturon) are sometimes detected in the Morcille River but only at trace levels (i.e. a few $n g$ L-1, Foulquier et al., 2015), without a contamination gradient from upstream to downstream thus revealing a lack of direct link with agricultural practices on the watershed.

Most of other pesticides frequently detected in the river (before and after the ban of diuron) belong to fungicides (Montuelle et al., 2010) and especially dimetomorph and tebuconazole (Rabiet et al., 2010; Foulquier et al., 2015), which can reach concentrations higher than 0.5 $\mu \mathrm{g} / \mathrm{L}$ during post-treatment periods due to their intensive use on vineyards (unpublished). In

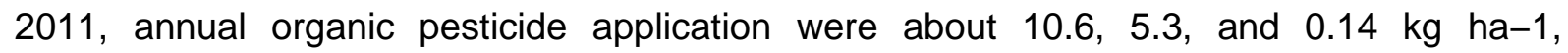
respectively, for active ingredients of fungicides, herbicides, and insecticides during the growing season (Peyrard et al., 2016). Increasing concentrations of PO43- are also observed from upstream to downstream (Pesce et al., 2010b). Mean PO43- recorded during the entire survey were $0.07 \pm 0.04 \mathrm{mg} / \mathrm{L}, 0.23 \pm 0.06 \mathrm{mg} / \mathrm{L}$ and $0.30 \pm 0.09 \mathrm{mg} / \mathrm{L}$ at the low contaminated, medium contaminated and high contaminated stations, respectively (data not shown). 


\subsection{Sampling procedure}

Samples of biofilms and water (for chemical analysis) were collected at three sampling stations located along the Morcille River and respectively called "low contaminated", "medium contaminated" and "high contaminated" stations (Fig. 1). The location of the three sampling sites was chosen to limit the influence of local effluents from potential point sources.

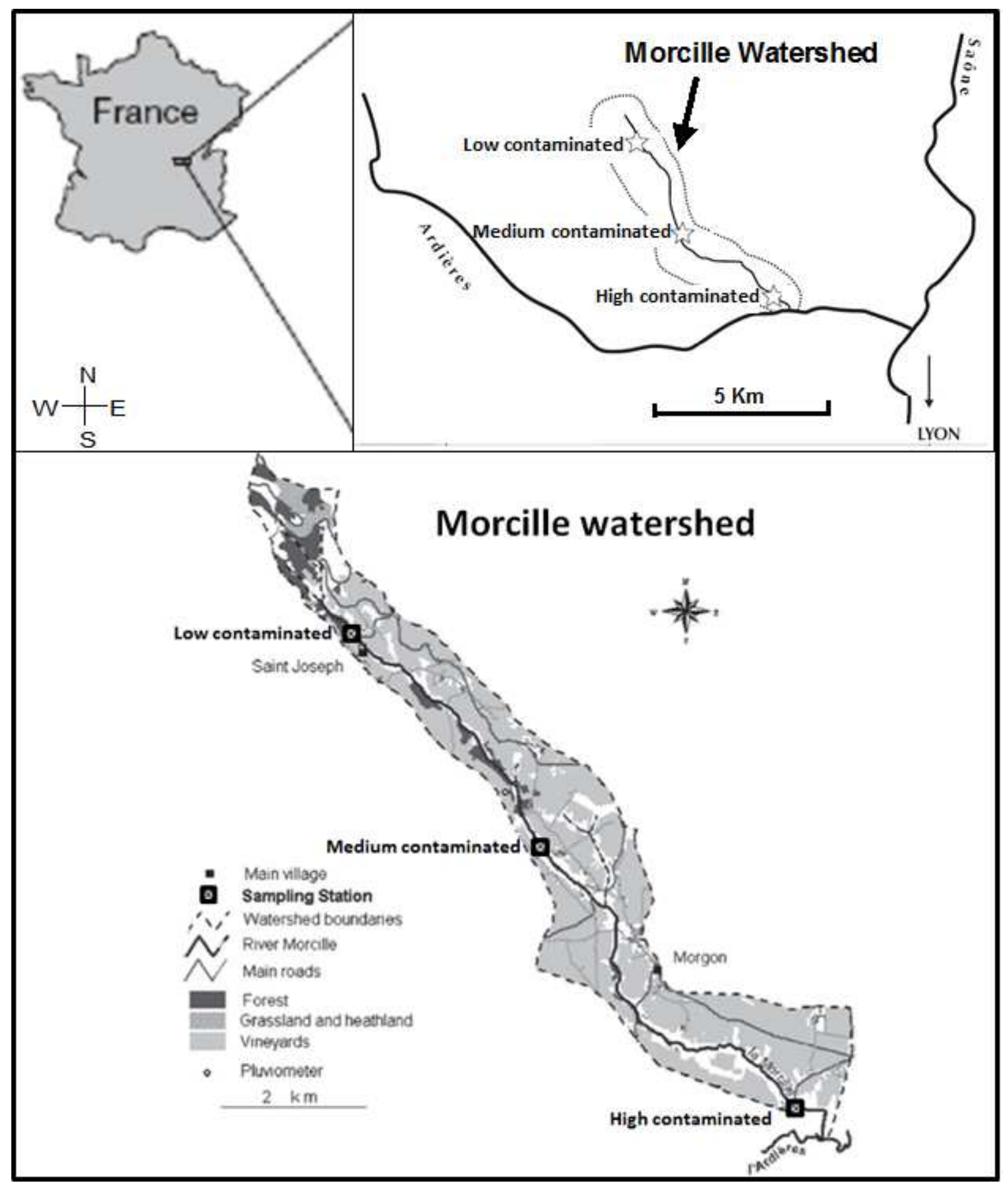

Fig. 1. Location of sampling stations along Morcille River (Beaujolais area, France). 
Biofilms were sampled on large glass slides $(220 \mathrm{~cm} 2)$ immersed for two months before each sample collection. To limit the variation in flow exposure, the immersion was performed using perforated plastic boxes which were placed about $5 \mathrm{~cm}$ below the water surface under similar light penetration conditions and perpendicular to the current (Morin et al., 2007). From January 2009 to December 2011, three slides were collected monthly at each of the three sampling stations and transported to the laboratory as described in Pesce et al. (2010b).

From October 2008 (start of biofilm colonization) to December 2011, water samples (1000 $\mathrm{mL}$ ) were collected twice or thrice a month at each sampling station to measure dissolved diuron concentrations. Diuron concentrations were determined by solid-phase extraction on Oasis HLB cartridges (60 mg, $3 \mathrm{~mL}$, Waters, France) followed by liquid chromatographytandem mass spectrometry (LC-MS/MS) as previously described (Pesce et al., 2013). The quantification limit was $0.01 \mu \mathrm{g} / \mathrm{L}$.

\subsection{PICT measurements}

At the laboratory, biofilms were carefully removed from each replicate slide using a razor blade and suspended in commercial mineral water (Volvic, France) to give a final concentration corresponding to $1 \mathrm{~cm} 2$ of biofilm per millimeter of suspension. Biofilm sensitivity to diuron was estimated via short-term photosynthetic bioassays using PSII quantum yield measurement of biofilm suspensions $(1.5 \mathrm{~mL}$ ) exposed for $4 \mathrm{~h}$ (3h30 under artificial light and $30 \mathrm{~min}$ in the dark) in $5 \mathrm{~mL}$ vials to nine increasing diuron concentrations (final concentrations ranging from about 0.2 to $2000 \mu \mathrm{g} / \mathrm{L}$ ). For each sample replicate (three per station), we ran four blanks and three analytical replicates with each of the nine increasing concentrations of diuron. PSII quantum yield was then determined with a PhytoPAM fluorometer using maximal photosynthetic efficiency of PSIl based on the maximal quantum yield at $665 \mathrm{~nm}$. More details can be found in Pesce et al. (2010b).

Statistical analysis of the dose-response curves obtained from short-term toxicity tests was conducted using the 'drc' package (Ritz and Streibig, 2005) in R. Dose-response curves were fitted to the data using the four-parameter log-log model given by the formula:

$$
\text { response }=c+\frac{d-c}{1+\exp \{b \times(\log (\text { Dose })-\log (e))\}}
$$

where $b$ is slope of the curve around e, parameters $c$ and $d$ are the lower and upper limits of the curve, respectively, and e is the the EC50, i.e. the dose producing a response half-way between the upper and lower limit. When the estimated lower limit was negative, $d$ was fixed at zero, and curves were refitted to the data. The response variable was expressed as percentage of the yield of the uncontaminated control assay. Based on EC50 estimates, analysis of variance (ANOVA) was used to test for differences in microbial community tolerance to diuron among stations and years. When a significant difference was observed, post hoc comparisons of means were performed with a Tukey's test. ANOVA was conducted on the whole dataset and then on two subsets corresponding to samples collected from May to November (i.e. during and after the main treatment period in vineyards, termed "posttreatment period" here) and from December to April. Data were log10 transformed to satisfy the assumption of normality and homogeneity of variance. Results of post hoc comparisons are shown in Supplementary Table 1. 


\section{Results and discussion}

\subsection{Can biofilms from the low contaminated station be considered as relevant references?}

The success of PICT approaches depends largely on the ability to detect differences in tolerance levels between a reference community and a chronically pre-exposed community (Blanck, 2002). Since it has been shown that the tolerance level of a non-exposed community (i.e. the "baseline tolerance") may vary between experiments or between regions, it is crucial to select the right reference site to implement long-term in situ PICT surveys ( Tlili et al., 2016). Here, the low contaminated upstream section of Morcille River was proposed as reference site due to its location in a mainly forested area with a small amount of vineyard plots (representing less than 7\% of the catchment area; Montuelle et al., 2010). As previously stated by Pesce et al. (2013), diuron concentrations measured in water samples collected at the low contaminated station (Fig. 1) were very low, with only 7 of the 80 samples collected showing concentrations higher than the quantification limit $(0.01 \mu \mathrm{g} / \mathrm{L})$ and only 2 samples showing concentrations slightly higher than the environmental quality standards (EQSs) for all surface waters covered under the WFD $(0.2 \mu \mathrm{g} / \mathrm{L}$; substance datasheet for priority substance No. 13: Diuron, CAS No. 330-54-1).

At this reference station, mean monthly EC50 values varied between 3.8 and $22.8 \mu \mathrm{g} / \mathrm{L}$ over the three years (Fig. 3). Mean (10.7 $\mu \mathrm{g} / \mathrm{L})$ and median $(9.7 \mu \mathrm{g} / \mathrm{L})$ values of the whole reference dataset were fairly similar, with a standard deviation of $4.8 \mu \mathrm{g} / \mathrm{L}$ (data not shown). Even if EC50 values obtained at the low contaminated station exhibited a small seasonal trend, especially in 2009 (Fig. 3A) and 2010 (Fig. 3B) when tolerance levels slightly increased in early summer before decreasing at the end of the year, the EC50 values measured on the all-year data showed only limited between-year variations (Fig. 4A). Mean annual EC50 values obtained at the low contamination station in 2009, 2010 and 2011 were $9.8( \pm 5.2) \mu \mathrm{g} / \mathrm{L}, 11.4( \pm 5.5) \mu \mathrm{g} / \mathrm{L}$ and $10.9( \pm 3.9) \mu \mathrm{g} / \mathrm{L}$, respectively, without significant difference between years (post hoc Tukey test, $p>0.05$ ). A similar result was observed with samples collected from May to November ("post-treatment period"; Fig. 4B) and from December to April (Fig. 4C). The relatively stable tolerance level observed at the low contaminated station thus clearly reflected the steady low level of diuron exposure recorded in this river section during the three-year survey period. This temporal stability over years further strengthens the reproducibility of the observations reported here, and validates the use of the biofilms from the low contaminated station as reference in the present study.

\subsection{Is PICT a relevant tool to assess the microbial community recovery following the decrease in diuron use in the Morcille watershed?}

One of the key as-yet-unresolved challenges for supporting the implementation of the European Water Framework Directive's ecological targets resides in the evaluation of ecological recovery following an improvement in water quality (Hering et al., 2013). While common biological indicators based on descriptors of community diversity (e.g. fish, invertebrates, bryophytes or diatoms) can sometimes be efficient to detect the effects of organic pollution, they generally indicate slow or no biological recovery following an improvement in water quality ( Hirst et al., 2004 and Ormerod, 2004). 


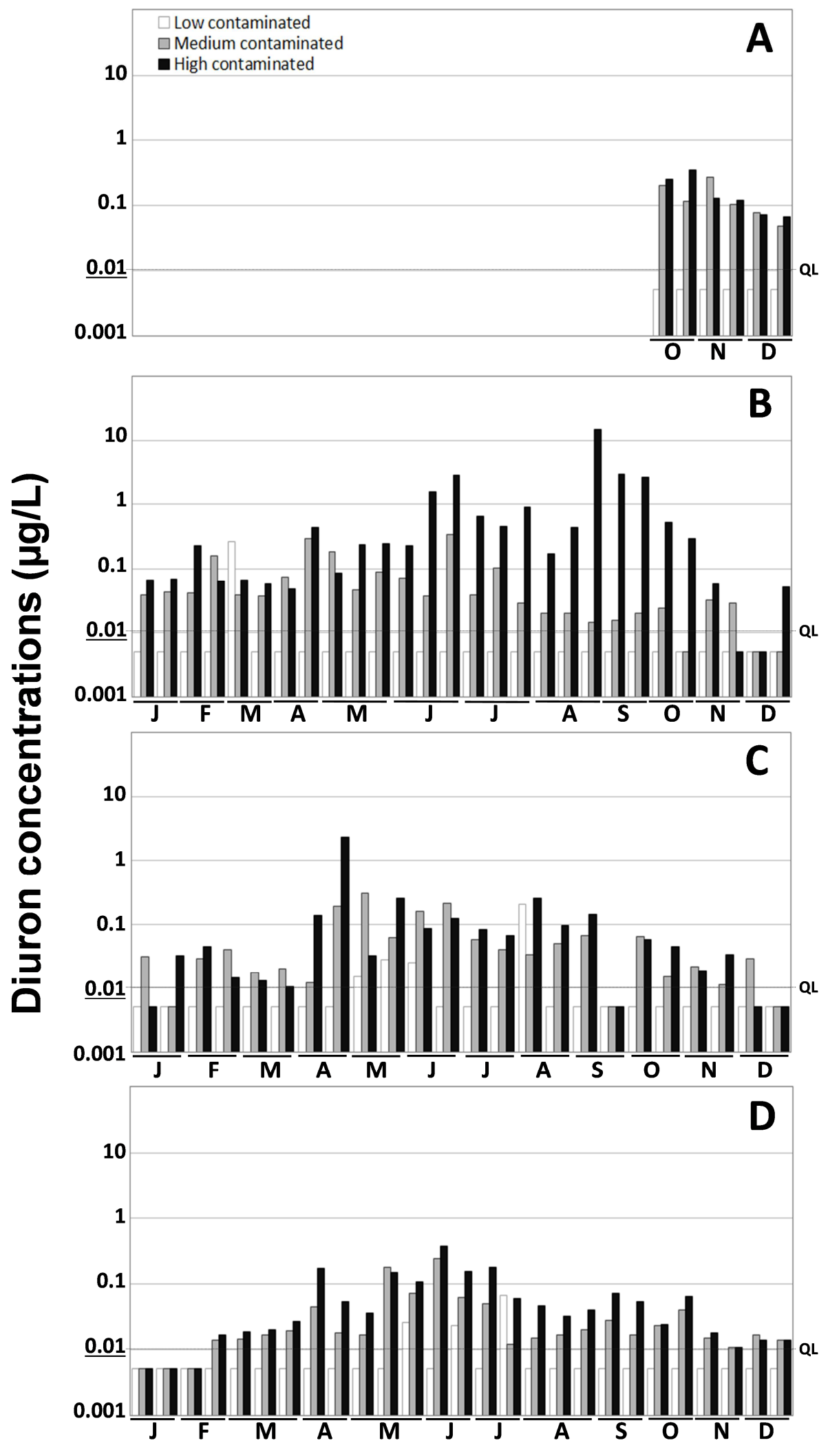

Fig. 2. Diuron concentrations $(\mu \mathrm{g} / \mathrm{L})$ measured in water samples collected twice or thrice a month at the three sampling stations in 2008 (B), 2009 (B), 2010 (C) and 2011 (D). Values under $0.01 \mu \mathrm{g} / \mathrm{L}$ were below the quantification limit (QL) making diuron concentrations impossible to determine with satisfactory precision. Letters on the horizontal axis indicate the month of the year. 
Since the PICT concept is based on the postulate that community-level tolerance to pollutants is correlated to the level of exposure in the environment, PICT approaches theoretically constitute a powerful tool to assess biological recovery following a decrease in water contamination (Tlili et al., 2016). Numerous studies performed in the Morcille River over the past decade have reported a diuron contamination gradient along the river (e.g. Montuelle et al., 2010 and Rabiet et al., 2010) with downstream-section concentrations sometimes higher than $10 \mu \mathrm{g} / \mathrm{L}$ (Pesce et al., 2009). In addition, it has been clearly shown that chronic exposure to pesticides (including diuron) in the contaminated sections of Morcille River led to a significant increase in diuron tolerance in phototrophic biofilm communities (e.g. Dorigo et al., 2007, Dorigo et al., 2010b, Pesce et al., 2010a and Pesce et al., 2010b). According to the ban of diuron, the present 3-year field study aimed to assess how PICT response could be 'substance-specific', thus reflecting the resulting progressive decrease in diuron concentrations in the Morcille River despite the persistence of a multi-contamination context.

Here, the gradient increase of diuron tolerance along Morcille River was still clearly evident in 2009, as all monthly EC50 values measured from January to November gradually increased from the low contaminated station, where they varied from 4 to $22 \mu \mathrm{g} / \mathrm{L}$, to the high contaminated station, where they varied from 10 to $87 \mu \mathrm{g} / \mathrm{L}$ (Fig. 3A). Indeed, in 2009, mean annual EC50 values significantly increased about two-fold between the low $(9.8 \mu \mathrm{g} / \mathrm{L})$ and the medium contaminated $(17.4 \mu \mathrm{g} / \mathrm{L})$ stations (post hoc Tukey test, $\mathrm{p}=0.043$ ) again by a further two-fold between the medium and the high contaminated ( $36.6 \mu \mathrm{g} / \mathrm{L})$ stations (Fig. $4 \mathrm{~A}$, post hoc Tukey test, $p=0.005$ ). However, the spatial differences in diuron tolerance were more pronounced during the May-to-November "post-treatment" period (Fig. 4B) than from December to April (Fig. 4C). As previously shown (Pesce et al., 2010b), the spatio-temporal variation in diuron sensitivity reflected spatio-temporal variation in diuron exposure levels during the biofilm colonization period (Fig. 2).

The ban on diuron in December 2008 resulted in a progressive decrease in diuron concentrations in the medium contaminated and high contaminated stations over the survey period (Fig. 2). However, diuron remained still present in the Morcille water, even three years after the ban revealing its persistence in the environment as well as a possible unlawful use. Detailed discussion on this chemical recovery following the change in agricultural practices can be found elsewhere (Pesce et al., 2013). Accordingly, we hypothesized that diuron tolerance would progressively decrease in river sections previously contaminated by high diuron concentrations. Indeed, while mean annual EC50 values measured at the low contaminated station remained relatively constant over years, we observed a clear decreasing trend at the high contaminated station during the survey (Fig. 4A), with mean

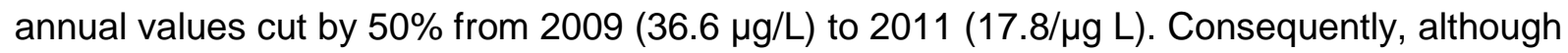
diuron tolerance was significantly higher at the high contaminated station than at the low contaminated station in 2009 (post-hoc Tukey test, $p<0.001$ ) and 2010 ( $p=0.001$ ), it was no longer significantly different in 2011 ( $p=0.072$ ). However, it should be noted that basal tolerance levels recorded at the high contaminated station remained relatively stable over years, as minimum annual EC50 values ranged from 8.9 in 2011 to $10.2 \mu \mathrm{g} / \mathrm{L}$ in 2009 ( Fig. 3 and Fig. 4A). This relative stability in basal tolerance levels is also illustrated in Fig. 4C, showing that inter-annual variations were very limited when considering EC50 values measured from December to April, which is the period with the lowest diuron concentrations in Morcille River (Fig. 2). These results suggest high reactivity of phototrophic biofilms which were able to recover swiftly (i.e. in less than a month) when diuron exposure decreased with seasonal (intra-annual) variations in exposure conditions. A translocation study in Morcille 
River showed that the tolerance level of phototrophic biofilms taken from the high contaminated station decreased about three-fold during the week following their transplantation to the low contaminated station, thus reaching roughly the same tolerance level as the native local community from this upstream river section ( Dorigo et al., 2010a). A quick recovery in biofilms transferred from a prometryn-contaminated station to a reference station was also reported (Rotter et al., 2011), with EC50 values decreasing two-fold in the space of just 17 days after translocation. Since there is now convincing evidence that the structural and functional recovery of phototrophic microbial communities after contamination episodes is conditioned by the immigration of non-previously-exposed (i.e. "pristine") populations ( Lambert et al., 2012 and Morin et al., 2012), it can be argued that the recoveryreactivity observed in the high contaminated station was favoured by the proximity of the low contaminated upstream reference section. This report thus reinforces the need to preserve river corridors, since connectivity is crucial in the context of ecological restoration of freshwater hydroecosystems (Kondolf et al., 2006).

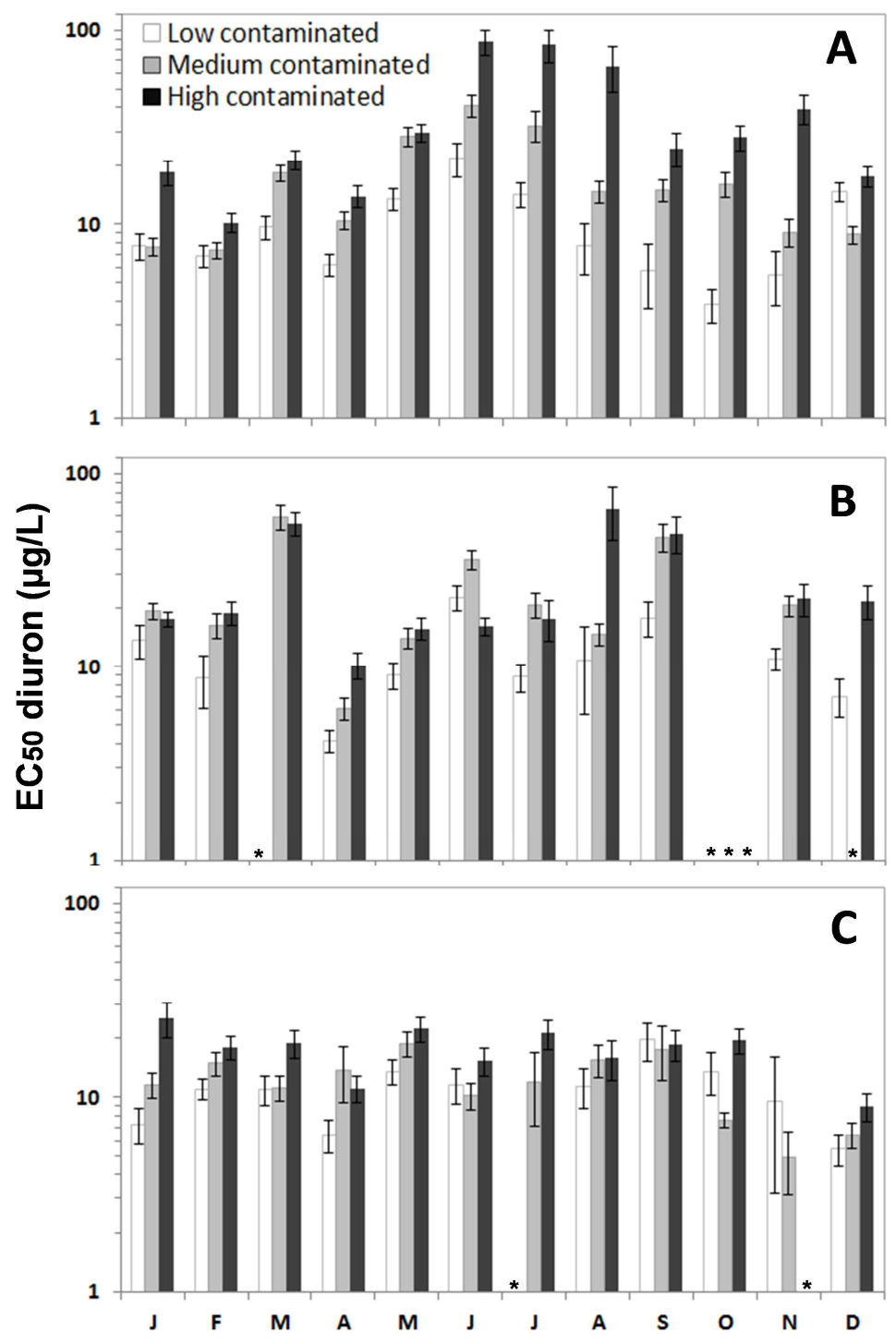

Fig. 3. Time-course (mean \pm standard deviation, $\mathrm{n}=3$ ) of effective diuron concentrations (EC50 in $\mu \mathrm{g} / \mathrm{L}$ ) obtained from short-term $(4 \mathrm{~h}$ ) inhibition tests of photosynthesis with biofilm communities collected monthly at the three sampling stations in 2009 (A), 2010 (B) and 2011 (C). *: not determined. 


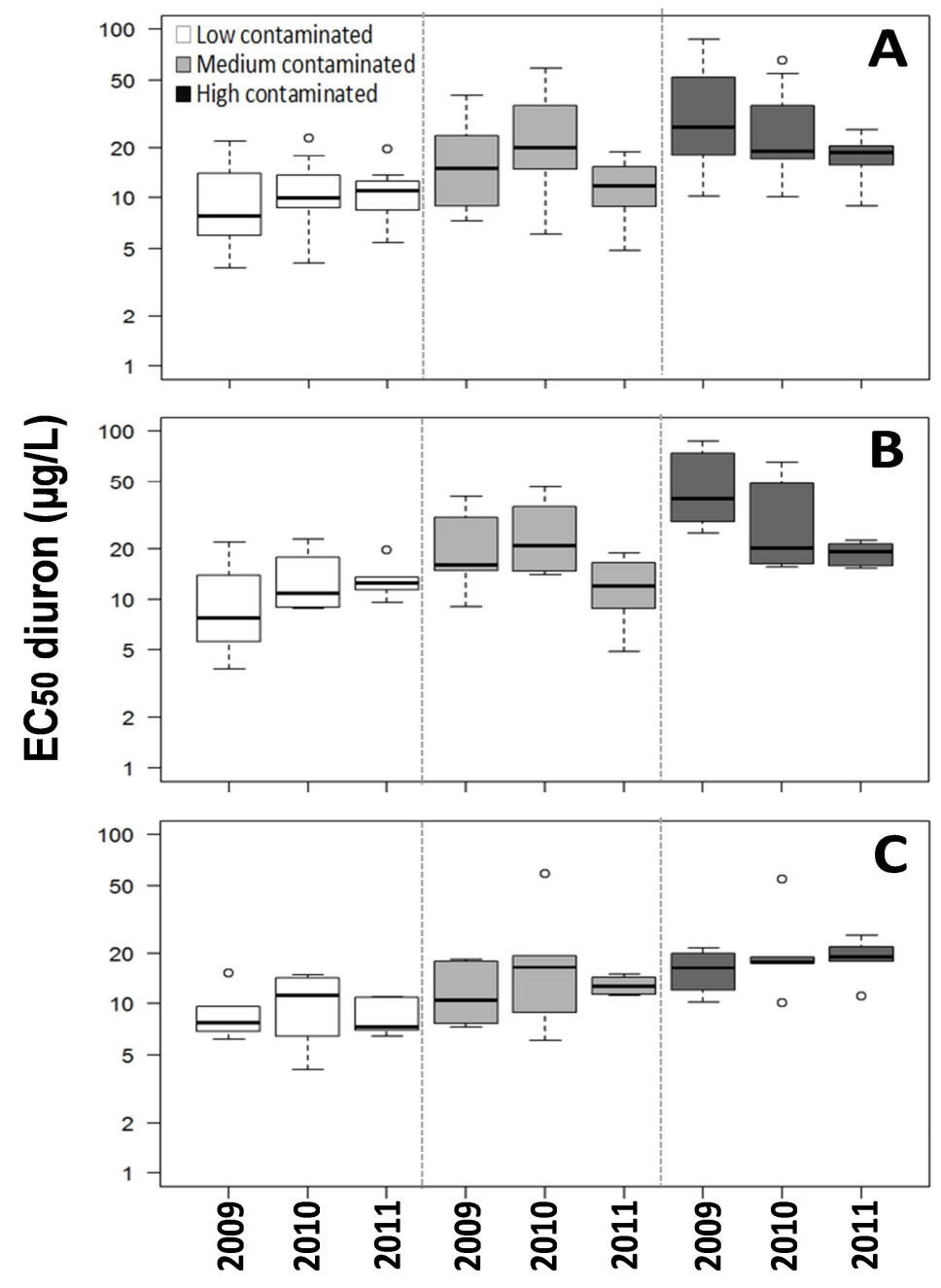

Fig. 4. Boxplot of EC50 values measured (A) over the entire year, (B) from May to November, and (C) from December to April. The horizontal line represents the median. The upper and lower limits of the box represent the 75th and 25th percentiles. The vertical lines above and below the box indicate the range of observed values within 1.5-times the interquartile range from the 75th and 25th percentiles. Values outside this range are considered outliers and indicated as points.

Finally, the evolution of tolerance levels recorded in the high contaminated station among years during the critical contamination period (i.e. May-November, Fig. 4B) clearly illustrated the long-term ecological recovery of Morcille River with a marked decreased in EC50 values. This decrease between 2009 and 2011 at the high contaminated station was observed whatever the parameter considered (i.e. mean or median EC50 values) but was clearest in the maximum EC50 values which were cut 4-fold between $2009(97.0 \mu \mathrm{g} / \mathrm{L})$ and $2011(22.4$ $\mu \mathrm{g} / \mathrm{L})$ ( Fig. 3 and Fig. 4B). This result is strongly consistent with the sharp decrease in maximum diuron concentrations recorded at this station (Fig. 2), where peak diuron concentration reached $15.0 \mu \mathrm{g} / \mathrm{L}$ in 2009 with four samples exhibiting concentrations higher than $2.5 \mu \mathrm{g} / \mathrm{L}$, compared to just $2.3 \mu \mathrm{g} / \mathrm{L}$ in 2010 and just $0.4 \mu \mathrm{g} / \mathrm{L}$ in 2011 . 
A downward trend in diuron tolerance level was also observed at the medium contaminated station but the decrease in EC50 values was mainly observed between 2010 and 2011, as statistically confirmed for the entire year (Fig. 4A, $p=0.016$ ) and the May-November period (Fig. $4 \mathrm{~B}, \mathrm{p}=0.030$ ) This is in accordance with the evolution of diuron concentrations at this station, which remained relatively stable between 2009 and 2010 before decreasing in 2011 (Fig. 2; Pesce et al., 2013). In 2011, mean annual EC50 value obtained at the medium contaminated station $(12.0 \pm 4.3 \mu \mathrm{g} / \mathrm{L}$ ) was similar (post hoc Tukey test, $\mathrm{p}=0.924)$ to that recorded at the reference station $(10.9 \pm 3.9 \mu \mathrm{g} / \mathrm{L})$, suggesting that diuron contamination level in the Morcille had become too low to induce an increase in tolerance at the medium contaminated station. It was previously stated that the threshold diuron exposure level for which increase in biofilm phototrophic community tolerance can be observed (after 7 weeks) is close to $0.08 \mu \mathrm{g} / \mathrm{L}$ (McClellan et al., 2008). Our results are fairly consistent with this assertion, since only two of the year-2011 samples exhibited concentrations higher than 0.08 $\mu \mathrm{g} / \mathrm{L}$ (Fig. 2), meaning that chronic exposure levels during the 2-month colonization were probably always lower than this threshold over the entire year. Taken together, results from the PICT approach support the assumption that the progressive decrease in diuron contamination of Morcille River may have led to the decrease in diuron tolerance capacities recorded in the phototrophic communities. This rapid biological recovery estimated with a functional endpoint contrasts with previous studies based on structural indicators of diatom diversity that have reported slower (from months to years) or no biological recovery following chemical restoration of stream waters (Hirst et al., 2004). Our results highlights that while biofilms can be considered "early warning systems" of toxicant contamination in aquatic ecosystems (Sabater et al., 2007), they also have the potential to give early signals of ecological benefits resulting from chemical recovery.

It has also to be noted that other photosystem inhibiting herbicides could also increase diuron tolerance level capacities, due to cotolerance processes (Knauer et al., 2010). Accordingly, the observed evolution of tolerance levels suggests that the diuron was not replaced by this kind of herbicides. This is consistent with the results from interviews with wine producers in the Morcille watershed, which revealed that the main herbicides used during the 2009-2011 period were aminotriazole, glyphosate, flumioxazin, aclonifen and the inorganic compound ammonium thiocyanate (Le Hénaff et al., personal communication).

\subsection{Perspectives for the use of the PICT approach as an ecological indicator of water quality}

As recently highlighted by a European group of researchers, PICT approaches offer a significant opportunity to better link the assessment of ecological and chemical status of ecosystems by providing causal analysis in effect-based monitoring of impacted field sites (Tlili et al., 2016). The present study offers new evidence that PICT has great potential as a metric of microbial community recovery following a decrease in toxicant exposure and confirms that PICT can be viewed as a powerful tool for assessing community recovery from environmental contamination (Blanck and Dahl, 1998) or wider general improvement of ecological status following restoration measures. Integrating PICT (on functional endpoints) into regulatory frameworks for assessing ecological status in aquatic ecosystems could lend the current battery of bioindicators more ecological relevancy and ecotoxicological specificity. However, this perspective still comes with a number of challenges (Tlili et al., 2016). 
One limitation for the use of PICT in monitoring programs is the difficulty to define baseline tolerance, which can vary with environmental conditions depending on target-community characteristics (Tlili and Montuelle, 2011). Interestingly, the relatively stable tolerance level observed here at the reference station during the entire survey period suggest that temporal changes remained very limited despite significant changes in environmental conditions (e.g. temperature, light...) due to seasonal variation. Note too that EC50 values measured in the low contaminated station of the Morcille were in the range of values $(2.6-15.2 \mu \mathrm{g} / \mathrm{L})$ recorded with several periphytic samples originated from a German river and cultivated for 3-12 weeks without diuron exposure (McClellan et al., 2008). The baseline tolerance of unexposed periphyton against diuron was set at $9 \mu \mathrm{g} / \mathrm{L}$ in this study (McClellan et al., 2008). The reference EC50 values found here were remarkably similar despite slight differences in the protocols used to perform the short-term tests between the two studies (e.g. use of DMSO to dissolve diuron, and a shorter acute exposure in McClellan et al., 2008). The fact that these two independent studies performed with periphytic communities exhibiting different characteristics produced largely comparable reference values together with the relative temporal stability observed over the three years studied here reopens an important question on the feasibility (or not) of defining reference levels or tolerance baselines for PICT approaches. This perspective, which could promote the field use of PICT as diagnostic tool, requires significantly more research attention to encourage the standardization of PICT measurements ( Lambert et al., 2015 and Tlili et al., 2016) and significantly greater extension to a large geographical scale in order to better estimate the weight of confounding effects of abiotic factors on the baseline tolerance estimates. One strategy to achieve this goal would be to select representative model compounds for chosen modes of action and to mobilize international collaborative projects in order to collect data from different regions (Tlili et al., 2016). Finally, modelling the influence of confounding factors could make measurements comparable in space and time by considering robust reference conditions defined at a larger scale (Coulaud et al., 2011).

\section{Conclusions}

In our study a direct link between a change in agricultural practice due to the ban of diuron, and an increase in the sensitivity of phototrophic biofilms to this herbicide was detected. This result reflects a biological recovery following the progressive decrease in diuron contamination, even if diuron remained detected in the Morcille water three years after its ban. PICT was thus successfully used to demonstrate community recovery from environmental contamination, reflecting its relevance as an indicator in ecosystem restoration. Indeed, the PICT response was "substance-specific", thus reflecting the resulting progressive decrease in diuron concentrations in the Morcille River despite the persistence of a multi-contamination context. Integrating PICT into regulatory frameworks for assessing ecological status in aquatic ecosystems could lend the current battery of bioindicators more ecological relevancy and ecotoxicological specificity

\section{Acknowledgments}

The authors thank A-T-T for proofreading the language content, Bernard Motte for support with field sampling, and the Irstea's Water Chemistry Laboratory in Lyon for physicalchemical data, especially Céline Guillemain and Corinne Brosse for their diuron analysis. Véronique Gouy and Guy Le Hénaff are also greatly acknowledged for sharing their 
expertise on agricultural practices and on the transfer of pesticides in the Morcille watershed. This project was supported by funding from the French National Office for the Aquatic Environment (ONEMA-ONEMA-Irstea agreement, action 26), and the LTER Zone Atelier du Bassin du Rhône (ZABR, Ardières-Morcille experimental watershed).

\section{References}

Blanck, H., 2002. A critical review of procedures and approaches used for assessing pollution induced community tolerance (PICT) in biotic communities. Hum. Ecol. Risk Assess. 8, 1003-1034.

Blanck, H., Dahl, B., 1998. Recovery of marine periphyton communities around a swedish marina after the ban of TBT use in antifouling paint. Mar. Pollut. Bull. 36, 437-442.

Blanck, H., Wängberg, S.A., Molander, S., 1988. Pollution-induced community tolerance - a new ecotoxicological tool, in: Cairns, J., Pratt, J.R. (Eds), Functional testing of aquatic biota for estimating hazards of chemicals, Philadelphia, ASTM STP 988, pp. 219-230.

Burns, A., Ryder, D.S., 2001. Potential for biofilms as biological indicators in Australian riverine systems. Ecol. Manag. Restor. 2, 53-63.

Coulaud, R., Geffard, O., Xuereb, B., Lacaze, E., Quéau, H., Garric, J., Charles, S., Chaumot, A., 2011. In situ feeding assay with Gammarus fossarum (Crustacea): Modelling the influence of confounding factors to improve water quality biomonitoring. Water Res. 45, 6417-6429.

Dorigo, U., Bérard, A., Bouchez, A., Rimet, F., Montuelle, B., 2010a. Transplantation of microbenthic algal assemblages to assess structural and functional recovery after diuron exposure. Arch. Environ. Contam. Toxicol. 59, 555-563.

Dorigo, U., Bérard, A., Rimet, F., Bouchez, A., Montuelle, B., 2010b. In situ assessment of periphyton recovery in a river contaminated by pesticides. Aquat. Toxicol. 98, 396-406.

Dorigo, U., Leboulanger, C., Bérard, A., Bouchez, A., Humbert, J.F., Montuelle, B., 2007. Lotic biofilm community structure and pesticide tolerance along a contamination gradient in a vineyard area. Aquat. Microb. Ecol. 50, 91-102.

Hering, D., Borja, A., Carstensen, J., Carvalho, L., Elliott, M., Feld, C.K., Heiskanen, A.S., Johnson, R.K., Moe, J., Pont, D., Solheim, A.L., van de Bund, W., 2010. The European Water Framework Directive at the age of 10: A critical review of the achievements with recommendations for the future. Sci. Total Environ. 408, 4007-4019.

Hering, D., Borja, A., Carvalho, L., Feld, C.K., 2013. Assessment and recovery of European water bodies: key messages from the WISER project. Hydrobiologia 704, 1-9.

Hirst, H., Chaud, F., Delabie, C., Jüttner, I., Ormerod, S.J., 2004; Assessing the short-term response of stream diatoms to acidity using inter-basin transplantations and chemical diffusing substrates. Freshwater Biol. 49,1072-1088.

Knauer, K., Leimgruber, A., Hommen, U., Knauert, S., 2010. Co-tolerance of phytoplankton communities to photosynthesis II inhibitors. Aquat Toxicol 96:256-263. 
Kondolf, G.M., Boulton, A.J., O'Daniel, S., Poole, G.C., Rahel, F.J., Stanley, E.H., Wohl, E., Bång, A., Carlstrom, J., Cristoni, C., Huber, H., Koljonen, S., Louhi, P., Nakamura, K., 2006. Process-based ecological river restoration: visualizing three-dimensional connectivity and dynamic vectors to recover lost linkages. Ecol. Soc. 11, 5.

Lambert, A.S., Morin, S., Artigas, J., Volat, B., Coquery, M., Neyra, M., Pesce, S., 2012. Structural and functional recovery of microbial biofilms after a decrease in copper exposure: Influence of the presence of pristine communities. Aquat. Toxicol. 109, 118-126.

Lambert, A.S., Pesce, S., Foulquier, A., Gahou, J., Coquery, M., Dabrin, A., 2015. Improved short-term toxicity test protocol to assess metal tolerance in phototrophic periphyton: toward standardization

of PICT approaches. Environ. Sci. Pollut. Res. 22, 4037-4045.

Louchart, X., Voltz, M., Andrieux, P., Moussa, R., 2001. Herbicide transport to surface waters at field and watershed scales in a Mediterranean vineyard area. J. Environ. Qual. 30, 98291.

McClellan, K., Altenburger, R., Schmitt-Jansen, M., 2008. Pollution-induced community tolerance as

a measure of species interaction in toxicity assessment. J. Appl. Ecol. 45, 1514-1522.

Montuelle, B., Dorigo, U., Bérard, A., Volat, B., Bouchez, A., Tlili, A., Gouy, V., Pesce, S., 2010. The periphyton as a multimetric bioindicator for assessing the impact of land use on rivers: an overview of the Ardières-Morcille experimental watershed. Hydrobiologia 657, 123141.

Morin, S., Lambert, A.S., Artigas, J., Coquery, M., Pesce, S., 2012. Diatom immigration drives biofilm recovery after chronic copper exposure. Freshwater Biol. 57, 1658-1666.

Morin, S., Vivas-Nogues, M., Duong, T.T., Boudou, A., Coste, M., Delmas, F., 2007. Dynamics of benthic diatom colonization in a cadmium/zinc-polluted river (Riou-Mort, France). Fund. Appl. Limnol. 168, 179-187.

Ormerod, S.J., 2004. A golden age of river restoration science? Aquat. Conserv. Mar. Freshwat. Ecosyst. 14, 543-549.

Pesce, S., Bouchez, A., Montuelle, B., 2011. Effects of organic herbicides on phototrophic microbial communities in freshwater ecosystems. Rev. Environ. Contam. Toxicol. 214, 87124.

Pesce, S., Lissalde, S., Lavieille, D., Margoum, C., Mazzella, N., Roubeix, V., Montuelle, B., 2010a. Evaluation of single and joint toxic effects of diuron and its main metabolites on natural phototrophic biofilms using a pollution-induced community tolerance (PICT) approach. Aquat. Toxicol. 99, 492-499.

Pesce, S., Margoum, C., Montuelle, B., 2010b. In situ relationships between spatio-temporal variations in diuron concentrations and phototrophic biofilm tolerance in a contaminated river. Water Res. 44, 1941-1949.

Pesce, S., Margoum, C., Rouard, N., Foulquier, A., Martin-Laurent, F., 2013. Freshwater sediment pesticide biodegradation potential as an ecological indicator of microbial recovery 
following a decrease in chronic pesticide exposure: A case study with the herbicide diuron. Ecol. Indic. 29, 18-25.

Pesce, S., Martin-Laurent, F., Rouard, N., Montuelle, B., 2009. Potential for microbial diuron mineralisation in a small wine-growing watershed: from treated plots to lotic receiver hydrosystem. Pest. Manag. Sci. 65, 651-657.

Peyrard, X., Liger, L., Guillemain, C., Gouy, V., 2016. A trench study to assess transfer of pesticides in subsurface lateral flow for a soil with contrasting texture on a sloping vineyard in Beaujolais. Environ. Sci. Pollut. Res. DOI 10.1007/s11356-015-4917-5

Rabiet, M., Coquery, M., Carluer, N., Gahou, J., Gouy, V., 2015. Transfer of metal(loid)s in a small vineyard catchment: contribution of dissolved and particulate fractions in river for contrasted hydrological conditions. Environ. Sci. Pollut. Res. 22, 19224-19239.

Rabiet, M., Margoum, C., Gouy, V., Carluer, N., Coquery, M., 2010. Assessing pesticide concentrations and fluxes in the stream of a small vineyard catchment - Effect of sampling frequency. Environ. Pollut. 158, 737-748.

Ritz, C., Streibig, J.C., 2005. Bioassay analysis using R. J. Stat. Softw. 12, 1-22.

Rotter, S., Sans-Piché, F., Streck, G., Altenburger, R., Schmitt-Jansen, M., 2011. Active biomonitoring of contamination in aquatic systems - An in situ translocation experiment applying the PICT concept. Aquat. Toxicol. 101, 228-236.

Sabater, S., Guasch, H., Ricart, M., Romani, A., Vidal, G., Klünder, C., Schmitt-Jansen, M., 2007. Monitoring the effect of chemical on biological communities. The biofilm as an interface. Anal. Bioanal. Chem. 387, 1425-1434.

Schmitt-Jansen, M., Altenburger, R., 2008. Community-level microalgal toxicity assessment by multiwavelength-excitation PAM fluorometry. Aquat. Toxicol. 86, 49-58.

Tlili, A., Blanck, H., Bouchez, A., Cássio, F., Eriksson, K.M., Morin, S., Montuelle, B., Navarro, E., Pascoal, C., Pesce, S., Schmitt-Jansen, M., Behra, R., 2016. Pollution induced community tolerance (PICT): towards an ecologically relevant risk assessment of chemicals in aquatic systems. Freshwater Biol. doi:10.1111/fwb.12558

Tlili, A., Montuelle, B., 2011. Microbial pollution-induced community tolerance, in: AmiartTriquet, C., Rainbow, P.S., Roméo, M. (Eds.), Tolerance to Environmental Contaminants. CRCpress. pp. 85-108.

WFD, 2000. Directive 2000/60/EC of the European Parliament and of the Council establishing a framework for the Community action in the field of water policy (Water Framework Directive) adopted on 23.10.2000, published in the Official Journal (OJ L 237) on 22.12.2000. 


\section{Appendix A. Supplementary data}

The following are Supplementary data to this article:

\begin{tabular}{|c|c|c|c|c|c|}
\hline \multicolumn{6}{|l|}{ Entire year } \\
\hline Year $=2009$ & $p$-value & Year $=2010$ & $p$-value & Year $=2011$ & $p$-value \\
\hline Low-Medium & 0.0433 & Low-Medium & 0.0087 & Low-Medium & 0.9243 \\
\hline Low-High & $<0.0001$ & Low-High & 0.0014 & Low-High & 0.0720 \\
\hline Medium-High & 0.0055 & Medium-High & 0.8660 & Medium-High & 0.1455 \\
\hline Station = Low & $p$-value & Station = Medium & $p$-value & Station = High & $p$-value \\
\hline $2009-2010$ & 0.7562 & $2009-2010$ & 0.2701 & $2009-2010$ & 0.5875 \\
\hline $2009-2011$ & 0.7514 & 2009-2011 & 0.3895 & 2009-2011 & 0.0366 \\
\hline $2010-2011$ & 0.9999 & 2010-2011 & 0.0165 & 2010-2011 & 0.3003 \\
\hline & & & & & \\
\hline \multicolumn{6}{|c|}{ May to November } \\
\hline Year $=2009$ & $p$-value & Year $=2010$ & $p$-value & Year $=2011$ & $p$-value \\
\hline Low-Medium & 0.0090 & Low-Medium & 0.0833 & Low-Medium & 0.8921 \\
\hline Low-High & $<0.0001$ & Low-High & 0.0275 & Low-High & 0.3859 \\
\hline Medium-High & 0.0058 & Medium-High & 0.8816 & Medium-High & 0.1688 \\
\hline Station $=$ Low & $p$-value & Station = Medium & $p$-value & Station $=$ High & $p$-value \\
\hline $2009-2010$ & 0.4339 & $2009-2010$ & 0.8511 & $2009-2010$ & 0.1028 \\
\hline $2009-2011$ & 0.3822 & $2009-2011$ & 0.0853 & $2009-2011$ & 0.0040 \\
\hline $2010-2011$ & 0.9956 & 2010-2011 & 0.0298 & 2010-2011 & 0.4314 \\
\hline & & & & & \\
\hline \multicolumn{6}{|c|}{ December to April } \\
\hline Year $=2009$ & $p$-value & Year $=2010$ & $p$-value & Year $=2011$ & $p$-value \\
\hline Low-Medium & 0.6556 & Low-Medium & 0.2401 & Low-Medium & 0.4257 \\
\hline Low-High & 0.2072 & Low-High & 0.0631 & Low-High & 0.0409 \\
\hline Medium-High & 0.6411 & Medium-High & 0.7409 & Medium-High & 0.4998 \\
\hline Station = Low & $p$-value & Station $=$ Medium & $p$-value & Station = High & $p$-value \\
\hline $2009-2010$ & 0.9734 & $2009-2010$ & 0.5198 & $2009-2010$ & 0.6855 \\
\hline 2009-2011 & 0.9908 & $2009-2011$ & 0.9485 & $2009-2011$ & 0.8521 \\
\hline 2010-2011 & 0.9373 & 2010-2011 & 0.7483 & 2010-2011 & 0.9483 \\
\hline
\end{tabular}

Supplementary Table 1: Results from post hoc Tukey's test comparing EC50 estimates among stations and years. Values in bold indicate significance at $p<0.05$. 